\title{
Analysis of Transient Response and Harmonic Disturbances on the Tanker's Electrical System Based on Simulation
}

\author{
Sardono Sarwito ${ }^{1}$, Eddy Setyo Koenhardono ${ }^{2}$, Kirana Putri Taradipa Martha ${ }^{3}$
}

\begin{abstract}
Basically a ship has a variety of conditions, namely cargo handling, anchoring, maneuvering, and sailing its requires large electricity consumption. The quality of the voltage is not good will cause damage to electrical equipment on board. Disturbances that occur in electrical system of MT. $X$ may result in a decrease in the performance of existing electrical equipment on the vessel and affect a certain condition as in loading-unloading conditions the time required for loading and unloading becomes longer due to interference with the electrical system. The MT.X tanker system has 5 (five) main busbars: BUS 1, FEEDER PANEL, DSB 2, DSB $3 \& 4$, and DSB 6. The MT tanker. $X$ has a generator of 3 units with a power of $680 \mathrm{kw}$ each, a frequency of $60 \mathrm{hz}$ and a voltage of $450 \mathrm{~V}$. Transient disturbance analysis under loading-unloading condition occurs transient response due to starting ballast pump where the voltage rises and then drops within 0.5 seconds with the highest value of $100.44 \%$ at 4.01 seconds and the lowest value is $99.50 \%$ to 4.81 can then reach steady state conditions at $\mathbf{9 9 . 9 \%}$, which does not exceed the IEEE standard limits. In harmonic disturbances under loading-unloading conditions, in the feeder panel connecting the harmonic source with load at the 5th order, the value of VIHD is $8.77 \%$, which exceeds the IEEE standard of 5\%. While the value of VTHD in loading and unloading conditions also exceeded the predefined standard limits. After installation of the filter, it can be seen that the value of VIHD at the 5th order in loadingunloading condition decreased to $3.6 \%$ after the installation of filter on feeder panel, or equal to decrease as much as $5.17 \%$. The decline in the value of VIHD has fulfilled the IEEE 519-2014 standard of 5\% on each individual order. Meanwhile, VTHD value in loading-unloading condition also decreased, from $11.18 \%$ to $7.02 \%$.
\end{abstract}

Keywords — Transient Response, Harmonics, Electrical System

\section{INTRODUCTION}

$\mathrm{I}_{\mathrm{n}}$ essence the ship has a variety of conditions including loading and unloading (handling of cargo), lego anchors (retaining), maneuvering (maneuvering), and sailing (sailing) which requires large electricity consumption[1]. Poor quality of the voltage will cause damage to electrical equipment on board [1]-[3]. The development of power systems in both the generator and the load will produce new problems concerning the stability system. In the use of two or more generators that work freely, the amount may change if the amount of power is unstable[3], [4]. A system will achieve stability when the mechanical power in the main generator drive with electrical power is channeled to the load.

Poor quality voltages can cause damage to electrical equipment on board [3], [5]. Causes of disturbance originating from within the system include abnormal voltages and currents, poor mounting, overloading, and material damage such as broken wire, broken insulators or insulated defects cords [4], [6]. When viewed in terms of the length of time the disturbance, it can be grouped

Sardono Sarwito, Department of Marine Engineering Sardono Sarwito, Department of Marine Engineering, Institut Teknologi Sepuluh Nopember, Surabaya 60111, Indonesia, Email: $\underline{\text { sarsan@its.ac.id }}$

Eddy Setyo Koenhardono,_Department of Marine Engineering Sardono Sarwito, Department of Marine Engineering, Institut Teknologi Sepuluh Nopember, Surabaya 60111, Indonesia, Email: eddy-koen@its.ac.id

Kirana Putri Taradipa Martha, Department of Marine Engineering, Institut Teknologi Sepuluh Nopember, Surabaya 60111, Indonesia, Email: kiranaptmartha@mhs.ne.its.ac.id into two temporary disturbances, which can be lost by itself or by deciding momentarily disturbed parts of the voltage source. The second is permanent disruption, where to free it necessary corrective action and / or get rid of the cause of the disorder. There are various kinds of disturbances that exist in an electrical system that is, transient response, harmonic, etc [6], [7].

Transient response is a performance that shows the speed of the system response in units of time at the transition phenomenon[6]. Harmonics is a disturbance that occurs in power distribution system due to the distortion of current wave and voltage [8], [9]. Basically, harmonics is a symptom of the formation of waves with different frequencies which are the multiplication of integers with their fundamental frequency. This is called the harmonic frequency that arises on the original waveform while the integer frequency multiplier is called the harmonic sequence number. In this study transient responses and harmonics related or influenced one another. At the time of incoming load, the network flow will automatically increase as well, the high current will affect the magnetization on the generator, which generator rotation will also decrease or in other words the rotation frequency decreases. Related to the problem, it will be done how to detect and improve transient response and harmonics. 


\section{METHOD}

\section{A. Transient Response}

Transient response is a performance that shows the speed of the system response in units of time at the transition phenomenon. Transient or transitional symptoms are the change of current or voltage values even both instantaneously or within a certain time period (in micro order seconds) in steady state. The cause is that can be from external factors and internal factors. Transient symptoms occur in circuits containing components or elements capable of storing energy such as inductors and / or capacitors. This symptom arises because the energy received or released by the component can not change instantaneously (current on the inductor and voltage on the capacitor).

The cause of the transient response is the determinant parameters, which usually occur due to open circuit, short circuit (short circuit), or switching, in source operation, etc. Transients are the looping of voltage and current variables that take place during the transition from one stable state to another. Changes in current, voltage during indirect is required and require better time to complete in milliseconds or even microseconds.

This rapid change can not, however, happen instantly or instantaneously because the transient process is obtained through energy exchange, which is usually stored in the magnetic field of the inductance or electric field of capacitance. The change of energy can not occur suddenly or suddenly because it will produce unlimited power (power is a derivative of energy $(\mathrm{P}=\mathrm{dW} / \mathrm{dt}$ ), which will not occur in real circumstances All changes of parameters when transient response then disappears, and will appear in a new steady state

In this case, the transient response can be regarded as the behavior of the circuit between two steady states, the old steady state (before the change) and the new steady state. The causes of transient response include: (a) Load switching (Load switching); (b) Switching capacitor (c) Recovery voltage

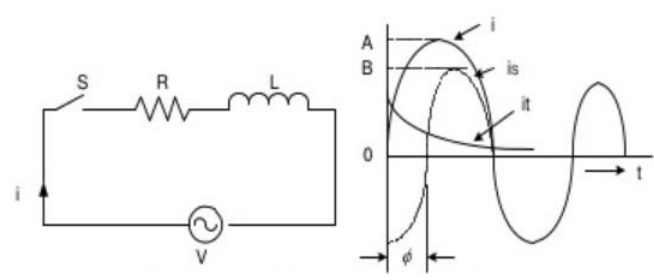

Figure 1 (a) Equivalent Circuit R-L and (b) Flow Shape For R-L Circuits In the current waveform for the obtained R-L circuit [6]

$$
\begin{aligned}
& \mathrm{i}=\text { initial current (ampere) } \\
& \mathrm{V}=\text { voltage }(\text { Volt }) \\
& \mathrm{R}=\text { resistance }(\mathrm{Ohm}) \\
& \mathrm{L}=\text { induction }(\text { Henri) } \\
& \text { is }=\text { steady state state current (Ampere) } \\
& \text { it }=\text { transient current (Ampere) } \\
& \mathrm{t}=\text { time (seconds) } \\
& \text { so: } \\
& \text { it }=\text { transient current (Ampere) } \\
& \mathrm{A}=\text { constant } \\
& \mathrm{R}=\text { resistance }(\text { Ohm }) \\
& \mathrm{L}=\text { inductance }(\text { Henri) }
\end{aligned}
$$

Specifications Transient Response is a specification of the observed system response from the moment of change of input signal / interference / load until incoming response in steady state. The benchmarks used to measure the quality of this transient response include:

- $\quad$ Time constan $(T)=$ Measurement time that states response speed, measured from $\mathrm{t}=0 \mathrm{~s} / \mathrm{d}$ response reaches $63.2 \%$ of the steady state response.

- $\quad$ Rise time $(\mathrm{TR})=$ Measures of time indicating the presence of a response, measured from a $5 \%$ to 95\% response of the steady state response.

- Settling time $(\mathrm{Ts})=$ Size of time that states response has entered $\pm 0.5 \%, \pm 2 \%$, or $\pm 5 \%$ of steady state response

- Delay time $(\mathrm{TD})=$ Size time indicating delay factor of output response to input, measured starting $\mathrm{t}=0 \mathrm{~s} / \mathrm{d}$ response reach $50 \%$ from steady state response.

- Overshoot $=$ The relative value that represents the ratio of the maximum response price that exceeds the steady state price compared to the steady state value.

The Steady State Response Specification is a system response specification observed from the moment the response enters the steady state state indefinitely (in practice the observation time is made during $\mathrm{Ts} \leq \mathrm{t} \leq$ 5Ts). The benchmarks used to measure the quality of the steady state response are, among others; steady state error

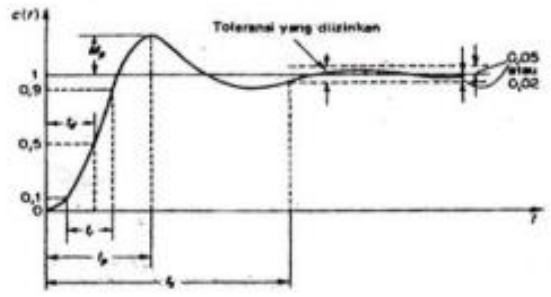

Figure 2 Ladder Response Curves [7]

\section{B. IEEE Standard}

According to the IEEE standard 106-2003 the ability of the generator to withstand under / over frequency phenomena is described in Figure 2.3 below 


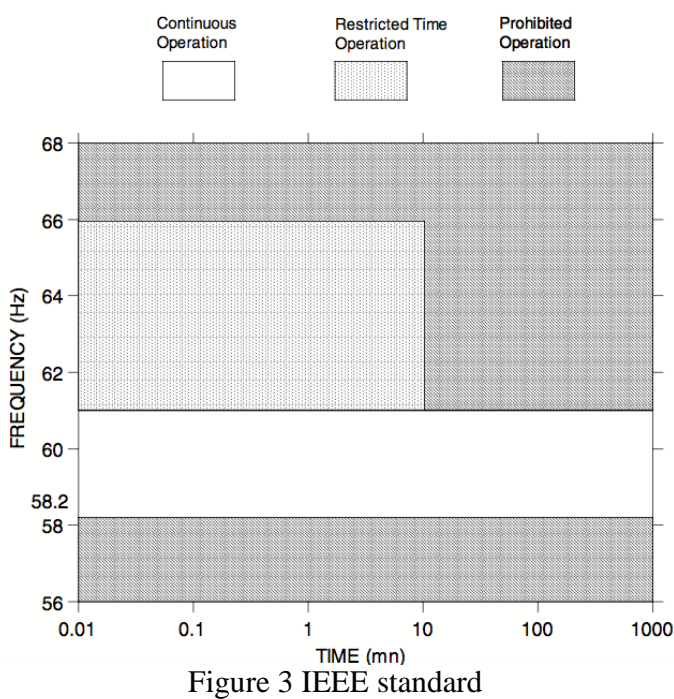

From the picture above can be taken explanation as follows:

- Under frequency is permitted up to $58.2 \mathrm{~Hz}$

- Over frequency is allowed up to $61 \mathrm{~Hz}$

For systems with a frequency of $50 \mathrm{~Hz}$, it is necessary to change the unit to $\%$ form in order to find the data. Then for frequency $50 \mathrm{~Hz}$,

- $\quad(58.2 / 60) \times 100 \%=97 \%$

- $(61 / 60) \times 100 \%=101.67 \%$

Then the frequency is not expected to touch the above value when steady state for system stability is maintained.

According to IEEE standard 1195, transient disturbance that can occur is voltage dip, voltage swell, over voltage and under voltage. The standard of the Voltage Dip can be seen in Figure 4 below:

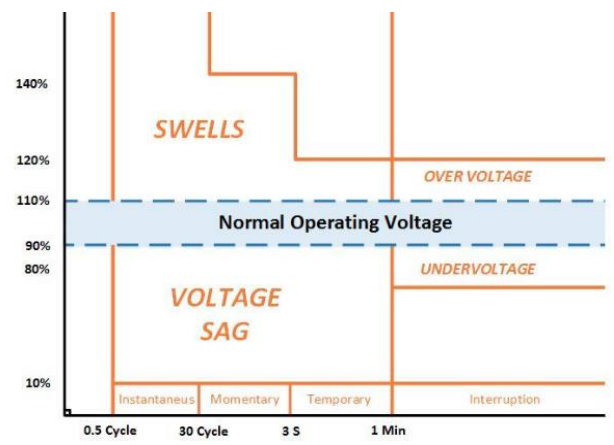

Figure 4 Voltage dips standard

From the picture 4 can be taken some explanation as follows:

- Normal operating voltage ranges from 90\% $110 \%$ of nominal voltage.

- Voltage sag / dip is a temporary drop in voltage up to the range of $10 \%-90 \%$ nominal voltage.

- Voltage swells are temporary rises of voltage up to $110 \%-180 \%$ of rated voltage.

- Duration of the dip voltage is divided into 3 categories: instantaneous ( 0.5 cycle -30 cycle), momentary (30 cycle - 3 seconds), and temporary ( 3 seconds -1 minute)

- Undervoltage and overvoltage are sustained interruption categories
- Voltage Dip are only allowed at $10 \%$ below and above nominal voltage values.

\section{Harmonic}

Harmonics is a disturbance that occurs in power distribution system due to the distortion of current wave and voltage[8], [9]. The cause of the occurrence of harmonics is the use of equipment that has non-linear characteristics. The existence of harmonic current in electric power system can not be eliminated. One way to decrease the harmonic current content is by a single passive frequency filter. Harmonics is a phenomenon arising from the operation of non-linear electrical loads so that the formation of high frequency waves which is a multiple of the fundamental frequency so that the shape is not sinusoidal. The relationship between harmonic and fundamental frequencies can be written as follows,

$$
\begin{aligned}
& F_{h}=n f_{i} \\
& \text { Fh }=\text { harmonic frequency } \\
& \text { n }=\text { wave multiplier (integer) } \\
& \text { fi = fundamental frequency. }
\end{aligned}
$$

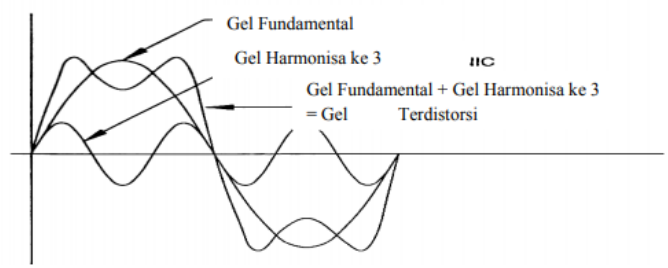

Figure 5 Distorted Waves, Fundamentals, Third Harmonics

\section{Effect of Harmonic Disturbance}

Harmonic disturbance leads to heat generation of cables and transformers, loss of loss and reduced efficiency of motor work. In addition there are some consequences that occur due to harmonics in the electrical system that is the emergence of mechanical vibrations in electrical panels, harmonics can cause additional torque at $\mathrm{KWH}$ meter, consequently rotation of the plate will occur more quickly or error occurs in $\mathrm{KWH}$ meter because the induction disk is designed only on basic frequency.

Voltage or current harmonics cause additional rugirugi on stator windings and rotor circuits, and laminate on the rotor and stator. These losses are greater than losses due to DC resistance due to Eddy current and skin effect. The harmonic current arising on the stator of the AC machine produces a motor action (positive harmonic slip, Sn). This action produces a torque shaft in the same direction as the harmonic field speed so that all positive sequential harmonics help the torque shaft rotation while the negative sequential harmonics is the opposite.

\section{E. How to Reduce Harmonic Disturbance}

When a power system experiences harmonic distortion problems, there are several basic ways to overcome them:

1. Reduce harmonic current generated by load

2. Add a filter to divert the current entering the system, or localize the harmonic current

3. Change the frequency response by using filters, inductors, and capacitors. 


\section{F. IEEE Standard 519-2014}

Recommended harmonic voltage limit:

1. Daily 2 nd percentile value is very short (3 seconds) should be less than 1.5 times the value given in Table 1 .

2. The value of the 95 th percentile (10 minutes) percentile should be smaller than the value given in Table 1.

At PCC, the system owner or operator must limit the harmonic line-to-neutral voltage in the following table 1:

Table 1 Recommended Harmonic Voltage Limit

\begin{tabular}{|c|c|c|}
\hline Bus voltage $V$ at PCC & $\begin{array}{c}\text { Individual } \\
\text { harmonic (\%) }\end{array}$ & $\begin{array}{c}\text { Total harmonic } \\
\text { distortion THD (\%) }\end{array}$ \\
\hline$V \leq 1.0 \mathrm{kV}$ & 5.0 & 8.0 \\
\hline $1 \mathrm{kV}<V \leq 69 \mathrm{kV}$ & 3.0 & 5.0 \\
\hline $69 \mathrm{kV}<V \leq 161 \mathrm{kV}$ & 1.5 & 2.5 \\
\hline $161 \mathrm{kV}<V$ & 1.0 & $1.5^{\mathrm{a}}$ \\
\hline
\end{tabular}

Based on Table 2.1 above, the recommended harmonic voltage limit for VIHD or voltage individual harmonic distortion is $5 \%$, while the harmonic voltage limit for VTHD or voltage total harmonic distortion is $8 \%$.

\section{G. Ship Electrial System}

The ship's electrical system is a system that operates within a ship's electrical installation. It can be clarified that the ship's electrical installation is one of the ship's working systems that deliver electrical energy for its use for the sustainability of the performance of a ship's operations. Without an electrical system on board, the ship will not be able to operate for operational activities. Because in essence electricity is the main requirement in carrying out operational activities on board. Without the electricity of course components such as motors, pumps, electronic devices, navigation equipment, and other components that require electricity, will not be able to operate. Electrical systems on ships can be started from a power generator unit that is a diesel generator which will then pass through various components of the distribution system for power supply[1], [3].

On the electrical system in the ship generally use at least 2 diesel generator. Because in operation in full load state can be used all generator available. However, when under normal load conditions then the use of generators can be done alternately so that the reliability of the generator can be maintained properly. The number of generators can be determined by calculating the number of power requirements of all the electrical components onboard. To determine the amount or amount of power required (determining the power of the generator) on the vessel, it must first be determined the power to be used by lamps for lighting, and electrical equipment (electric motors) (Sarwito, 1995). From the calculation tesebut obtained how many generators are needed with the power in accordance with the needs of power on the ship.

\section{H. Generator}

The generator is a large dynamo that functions as a power plant. The function of the generator is to convert mechanical energy into electrical energy. There are two main components in the electrical generator, the stator (the silent part) and the rotor parts that move. Based on the type of electric current generated, the electric generator is divided into 2 kinds, namely AC generator and DC generator. The alternating current generator (AC) is known as the alternator. The generator is expected to supply electricity during interruption, in which the supply is used for priority loads. While the generator set (generator set) is part of the generator.

\section{Induction Motor}

An induction motor or so-called asynchronous motor is an electric motor that converts electrical energy into mechanics. In principle is also affected by the rotating field, the rotation of the induction motor is caused by the rotating field (rotating flux) produced by the field coil on the stator. It is said to be an induction motor because the new motor can work when the rotor conductor is induced by the magnetic rotating field on the stator. This asynchronous motor works based on the difference between stator field rotation (Ns) and rotation of rotor $(\mathrm{Nr})$. It says motor slip because the motor rotates when $\mathrm{Ns}>\mathrm{Nr}[10],[11]$.

\section{J. Ship Condition}

Grouping based on ship activity above aims to facilitate in determining the load factor of each equipment, because not all electrical equipment on the ship is operated continuously. So according to Sarwito (1995) in the calculation of the determination of the generator has several views to determine the operational conditions of ships such as:

- Two Conditions: sail and berthing.

- Four conditions: sailing, leaving port, loading and unloading, and at harbor.

- Eight conditions: sailing, leaving the harbor, loading and unloading, and at harbors all in day and night conditions.

The maximum electrical load requirement is also important to know to determine the generator capacity required for generators to supply the maximum power requirements on the ship. While the minimum requirement is used to determine the configuration of the appropriate power system and to determine when the generator is in operation. Sarwito (1995) says there are three groups of load on the ship that must be served by the generator based on their respective functions:

- Load on the gastric deck (hull part

- Load in the form of electric motors of power planes in ship machinery systems (machinery parts)

- Load in the form of electronics, lighting, communication equipment, and navigation systems that support the ship's electrical system (electrical load)

\section{K. Overvoltage}

Overvoltage (Voltage over) is an increase in effective value of voltage to exceed 110 percent of the nominal voltage when it exceeds one minute. Overvoltage can be caused by load switching operations such as switching off at large loads, energizing capacitor banks. 


\section{Undervoltage}

Undervoltage is a decrease in the effective value of the voltage to exceed 90 percent of the nominal voltage when it exceeds one minute. Undervoltage can be caused by load switching operations such as switching on loads, bank switching capacitors.

\section{RESULTS AND DISCUSSION}

In this final project, the analysis is done by making simulation to know the transient response and harmonics disruption at 4 condition of the ship that is loadingunloading, sailing, anchoring, and maneuvering. To know the disturbance that exist in 4 condition, need to be simulated by using single line diagram data arranged in software simulation. After the compilation of single line data on software, do load flow analysis to determine whether single line diagram is connected with busbar. after doing load flow, then that is doing transient analysis and harmonics. (Table 2- 4)

Table 2 Data used for loading-unloading condition

\begin{tabular}{|c|c|c|c|c|}
\hline Nama Peralatan & $\mathrm{kW}$ & A & $\mathrm{V}$ & $\mathrm{Hz}$ \\
\hline Ballast Pump & 200 & 315 & 450 & 60 \\
\hline Ballast Pump & 200 & 315 & 450 & 60 \\
\hline Boiler Fan 1 & 55 & 59 & 450 & 60 \\
\hline Boiler Fan 1 & 55 & 59 & 450 & 60 \\
\hline Inert Gas Fan & 75 & 117 & 450 & 60 \\
\hline Inert Gas Fan & 75 & 117 & 450 & 60 \\
\hline Hydr Oil Pump & 100 & 165 & 450 & 60 \\
\hline Hydr Oil Pump & 100 & 165 & 450 & 60 \\
\hline Low Press Pump & 11 & 19.8 & 450 & 60 \\
\hline Compressor & 55 & 128 & 450 & 60 \\
\hline Hydr Pump Crane & 100 & 165 & 450 & 60 \\
\hline Ecr Ac & 3.75 & 7 & 450 & 60 \\
\hline Workshop Cooler & 3.75 & 7 & 450 & 60 \\
\hline Turning Gear & 3.7 & 7.2 & 450 & 60 \\
\hline Overhead Crane & 5 & 10 & 450 & 60 \\
\hline Fo Purifier & 5.5 & 9.1 & 450 & 60 \\
\hline M/E Lo Purifier & 5.5 & 9.1 & 450 & 60 \\
\hline G/E Lo Purifier & 3.7 & 6.5 & 450 & 60 \\
\hline Fo Shifter Pump & 3.7 & 7 & 450 & 60 \\
\hline Cargo Oil Turbine Lo & 1 & 2 & 450 & 60 \\
\hline Ejector Pump & 5.5 & 9.9 & 450 & 60 \\
\hline Distilate Pump & 1.5 & 2.8 & 450 & 60 \\
\hline Hyd Oil Pump For Valve & 1.5 & 3.4 & 450 & 60 \\
\hline Hyd Oil Pump For Valve & 1.5 & 3.4 & 450 & 60 \\
\hline \multicolumn{5}{|l|}{ 3.5 Ton Prov Crane } \\
\hline Hoisting & 7.5 & 13.2 & 450 & 60 \\
\hline Slewing & 2.2 & 4.2 & 450 & 60 \\
\hline Galley Ac & 3 & 5.89 & 450 & 60 \\
\hline Prov Ref Comp 1 & 3.7 & 12.5 & 450 & 60 \\
\hline Meat & 0.08 & 1.4 & 450 & 60 \\
\hline Vege & 0.08 & 1.4 & 450 & 60 \\
\hline Disposer Galley & 0.9 & 1.9 & 450 & 60 \\
\hline Galley Exh Fan & 1.5 & 3.3 & 450 & 60 \\
\hline Sanitary Exh Fan 1 & 1.5 & 3.3 & 450 & 60 \\
\hline \multicolumn{5}{|l|}{ 0.9 Ton Prov Crane } \\
\hline Hoisting & 2.2 & 4.2 & 450 & 60 \\
\hline Slewing & 0.75 & 1.6 & 450 & 60 \\
\hline
\end{tabular}

Table 3 Data used for sailing condition

\begin{tabular}{lllll}
\hline \hline \multicolumn{1}{c}{ Nama Peralatan } & $\mathrm{kW}$ & $\mathrm{A}$ & $\mathrm{V}$ & $\mathrm{Hz}$ \\
\hline Steering Gear & 50 & 82 & 450 & 60 \\
Boiler Fan & 55 & 59 & 450 & 60 \\
Boiler Fan & 55 & 59 & 450 & 60 \\
Hydraulic Oil Pump & 100 & 165 & 450 & 60 \\
Hydraulic Oil Pump & 100 & 165 & 450 & 60 \\
Compressor & 55 & 128 & 450 & 60 \\
Ecr Ac & 3.75 & 7 & 450 & 60 \\
Lathe & 1.5 & 3.2 & 450 & 60 \\
Drill Machine & 0.4 & 1.25 & 450 & 60 \\
Grinder & 0.75 & 1.57 & 450 & 60 \\
Turning Gear & 3.7 & 7.2 & 450 & 60 \\
Sewage Treatment & 1.5 & 3 & 450 & 60 \\
Fo Purifier & 5.5 & 9.1 & 450 & 60 \\
M/E Lo Purifier & 5.5 & 9.1 & 450 & 60 \\
G/E Lo Purifier & 3.7 & 6.5 & 450 & 60 \\
Fo Shifter Pump & 3.7 & 7 & 450 & 60 \\
Ejector Pump & 5.5 & 9.9 & 450 & 60 \\
Distilate Pump & 1.5 & 2.8 & 450 & 60 \\
Hyd Oil Pump For Valve Control Sys 1 & 1.5 & 3.4 & 450 & 60 \\
Hyd Oil Pump For Valve Control Sys 2 & 1.5 & 3.4 & 450 & 60 \\
Life\&Rescue Boat Winch Sb Side & 18 & 33 & 450 & 60 \\
Life Boat Winch Port Side & 3.7 & 7.3 & 450 & 60 \\
Galley Ac & 0.4 & 1 & 450 & 60 \\
Galley Ac & 3 & 5.89 & 450 & 60 \\
Prov Ref Comp 1 & 3.7 & 12.5 & 450 & 60 \\
Prov Ref Comp 2 & 3.7 & 12.5 & 450 & 60 \\
Meat & 0.08 & 1.4 & 450 & 60 \\
Vege & 0.08 & 1.4 & 450 & 60 \\
Disposer Galley & 0.9 & 1.9 & 450 & 60 \\
GALLEY EXH FAN & 1.5 & 3.3 & 450 & 60 \\
Galley Exh Fan & 1.5 & 3.3 & 450 & 60 \\
Sanitary Exh Fan 1 & 1.5 & 3.3 & 450 & 60 \\
Sanitary Exh Fan 1 & 1.5 & 3.3 & 450 & 60 \\
Hot Water Circ Pump & 0.4 & 1 & 450 & 60 \\
& & & & \\
\hline \hline & & & & \\
& & & & \\
\hline
\end{tabular}

Table 4 Data used for anchoring condition

\begin{tabular}{lllll}
\hline \hline \multicolumn{1}{c}{ Nama Peralatan } & $\mathrm{kW}$ & $\mathrm{A}$ & $\mathrm{V}$ & $\mathrm{Hz}$ \\
\hline Compressor & 55 & 128 & 450 & 60 \\
Hydraulic Oil Pump & 100 & 165 & 450 & 60 \\
Hydraulic Oil Pump 2 & 100 & 165 & 450 & 60 \\
Ecr Ac & 3.75 & 7 & 450 & 60 \\
Workshop Cooler & 3.75 & 7 & 450 & 60 \\
Fo Purifier & 5.5 & 9.1 & 450 & 60 \\
M/E Lo Purifier & 5.5 & 9.1 & 450 & 60 \\
G/E Lo Purifier & 3.7 & 6.5 & 450 & 60 \\
Fo Shifter Pump & 3.7 & 7 & 450 & 60 \\
Ejector Pump & 5.5 & 9.9 & 450 & 60 \\
Distilate Pump & 1.5 & 2.8 & 450 & 60 \\
Galley Ac & 3 & 5.89 & 450 & 60 \\
Prov Ref Comp 1 & 3.7 & 12.5 & 450 & 60 \\
Meat & 0.08 & 1.4 & 450 & 60 \\
Vege & 0.08 & 1.4 & 450 & 60 \\
Disposer Galley & 0.9 & 1.9 & 450 & 60 \\
Galley Exh Fan & 1.5 & 3.3 & 450 & 60 \\
Sanitary Exh Fan 1 & 1.5 & 3.3 & 450 & 60 \\
\hline \hline
\end{tabular}


Table 5 Data used for loading-unloading condition

\begin{tabular}{lcccc}
\hline \hline \multicolumn{1}{c}{ Nama Peralatan } & $\mathrm{k}$ & $\mathrm{A}$ & $\mathrm{V}$ & $\mathrm{Hz}$ \\
\hline Steering Gear & 50 & 82 & 450 & 60 \\
Boiler Fan & 55 & 59 & 450 & 60 \\
Compressor & 55 & 59 & 450 & 60 \\
Hydraulic Oil Pump & 100 & 165 & 450 & 60 \\
Hydraulic Oil Pump & 100 & 165 & 450 & 60 \\
Ecr Ac & 3.75 & 7 & 450 & 60 \\
Workshop Cooler & 3.75 & 7 & 450 & 60 \\
Fo Purifier & 5.5 & 9.1 & 450 & 60 \\
M/E Lo Purifier & 5.5 & 9.1 & 450 & 60 \\
G/E Lo Purifier & 5.5 & 9.1 & 450 & 60 \\
Fo Shifter Pump & 3.7 & 6.5 & 450 & 60 \\
Galley Ac & 3.7 & 7 & 450 & 60 \\
Prov Ref Comp & 3.7 & 12.5 & 450 & 60 \\
Meat \& Vege & 0.16 & 2.8 & 450 & 60 \\
Disposer Galley & 0.9 & 1.9 & 450 & 60 \\
Galley Exh Fan & 1.5 & 3.3 & 450 & 60 \\
Sanitary Exh Fan 1 & 1.5 & 3.3 & 450 & 60 \\
& & & & \\
\hline \hline
\end{tabular}

\section{A. Transient Response simulation}

In this transient response simulation, the authors used four ship conditions: loading-unloading, sailing, anchoring, and maneuvering as case study scenarios in the simulation.

In the first scenario the loading-unloading condition, where the largest load on the condition that is on the ballast pump of $200 \mathrm{~kW}$. In loading unloading conditions, the ballast pump used is 2 units. The simulation is done to get the stability value of transient response when the largest load is done starting.

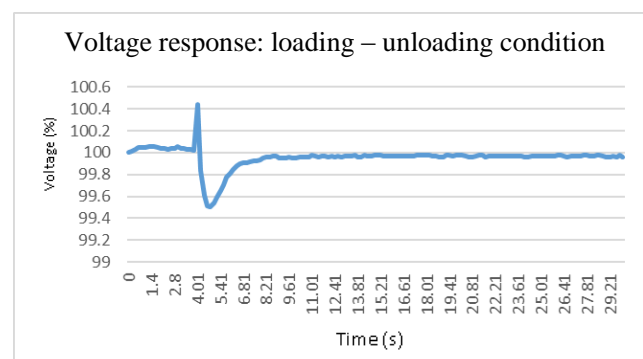

Figure 6. Voltage response: loading - unloading condition

In loading-unloading conditions, transient response occurs due to starting ballast pump where the voltage rises and then drops within 0.5 seconds with the highest value of $100.44 \%$ at 4.01 seconds and the lowest value is $99.50 \%$ in the 4th second, 81 can then reach steady state conditions at $99.9 \%$. Under loading-unloading conditions the transient response conditions still meet the standards and can be classified as stable.

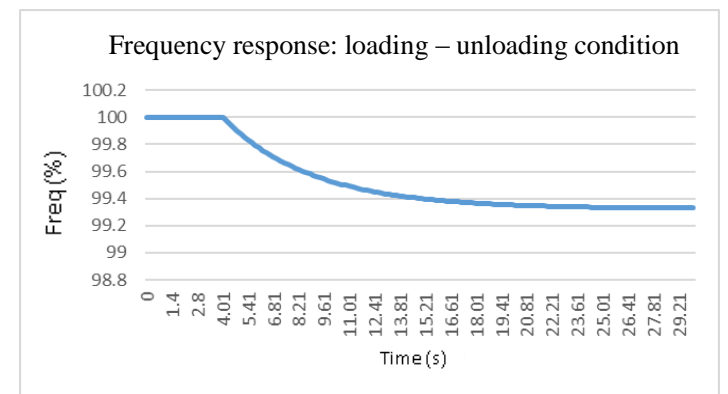

Figure 7. Frequency response: loading - unloading condition
Graph above shows the frequency response in the simulation of loading-unloading conditions, indicating a transient response due to the starting of the ballast pump where the frequency decreases up to $99.3 \%$ and is instantly stable at that value. The value still meets the standards and the system is still allowed to operate.

\section{B. Harmonics Simulation}

After the electrical system has been compiled on the software, then the load flow analysis must be simulated to get the value of harmonics and where the location of harmonics on the electrical system it happens. Simulation results will appear if there is a harmonic value that exceeds the specified standard limit.

Here is the VTHD value obtained from the simulation of harmonics with simulation software under loadingunloading conditions without using passive harmonic filters found in the table

Table 6. Voltage total harmonic distorsion

\begin{tabular}{llll}
\hline \multicolumn{4}{c}{ VTHD (VOLTAGE TOTAL HARMONIC DISTORTION) } \\
\hline \multicolumn{4}{c}{ BUSBARt - No Filter - Loading Unloading } \\
\hline BUS 1 & kV & \multicolumn{1}{c}{ Fund. \% } & THD \% \\
DSB 2 & 0.450 & 100.00 & 11.18 \\
DSB 3\&4 & 0.450 & 100.00 & 11.18 \\
DSB 6 & 0.450 & 100.00 & 11.18 \\
FEEDER PANEL & 0.450 & 100.00 & 11.18 \\
Cable76 & 0.450 & 100.00 & 11.18 \\
Cable78 & 0.450 & 99.90 & 11.28 \\
Cable80 & 0.450 & 99.90 & 11.28 \\
Cable82 & 0.450 & 99.74 & 11.32 \\
\hline \multicolumn{4}{l}{} \\
\hline
\end{tabular}

In this loading-unloading condition, THD value is $11.18 \%, 11.28 \%, 11.32 \%$ which means that it has exceeded the maximum THD\% ie $8 \%$.

In addition to getting VTHD values, from this simulation also get the value of VIHD which is the value of Individual Harmonic Distortion on each order of harmonics. on the feeder panel connected to the source of harmonics has a value of VIHD at the 5th order of $8.77 \%$.

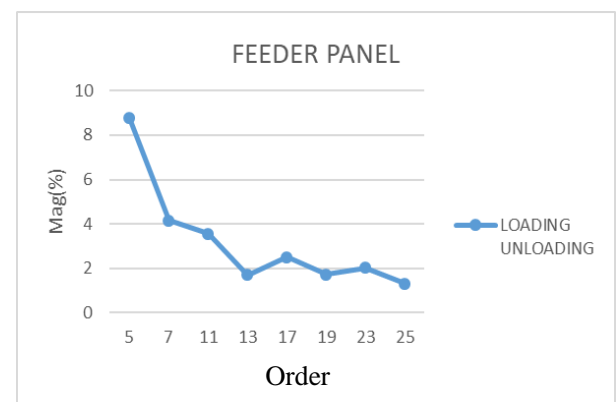

Figure 8. Voltage Drop: loading - unloading condition

After the installation of passive filters on the feeder panel in loading-unloading conditions (Figure 9) 


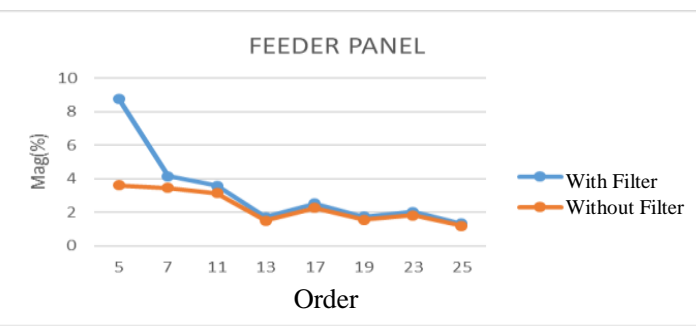

Figure 9. Voltage Drop with and without filter per order

From the Figure 9 it can be seen that the value of VIHD at the 5th order in loading-unloading conditions decreased to $3.6 \%$ after the installation of filters on the feeder panel, or equal to decreased by $5.17 \%$. The decline in the value of VIHD has fulfilled the IEEE 5192014 standard of $5 \%$ on each individual order. Meanwhile, VTHD value in loading-unloading condition also decreased, from $11.18 \%$ to $7.02 \%$. The decrease in VTHD values can be seen in the Figure 10.

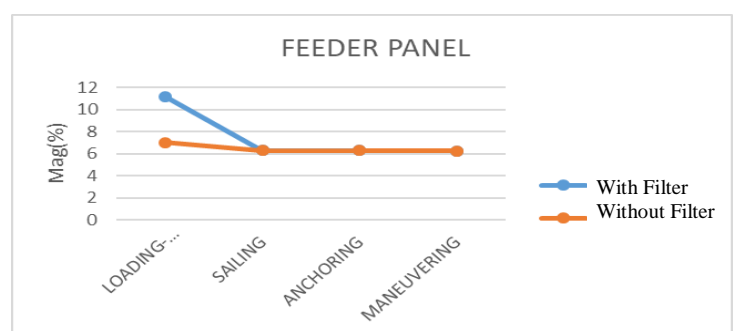

Figure 10. Voltage Drop with and without filter per condition

After installing passive filters on the feeder panel in loading-unloading conditions, the VTHD value decreased by $4.16 \%$ to $7.02 \%$ which the VTHD value has complied with IEEE 519-2014 standard of 8\%.

\section{CONCLUSION}

After performing the analysis using ETAP 12.6.0 simulation on MT tanker electrical system. X, it can be concluded that is: (1) In transient response and harmonic disturbance analysis performed by ETAP 12.6.0 simulation yield the following value In loadingunloading conditions, transient response occurs due to starting ballast pump where the voltage rises and then drops within 0.5 seconds with the highest value of $100.44 \%$ at 4.01 seconds and the lowest value is $99.50 \%$ in the 4th second, 81 can then reach steady state conditions at $99.9 \%$. Under loading-unloading conditions the transient response conditions still meet the standards and can be classified as stable. frequency response in the simulation loading-unloading conditions, indicating a transient response due to the starting of the ballast pump where the frequency decreases up to $99.3 \%$ and is directly stable at that value. The value still meets the standards and the system is still allowed to operate. In this loading-unloading condition, THD value is $11.18 \%$, $11.28 \%, 11.32 \%$ which means that it has exceeded the maximum THD $\%$ ie $8 \%$. In addition to getting VTHD values, from this simulation also get the value of VIHD which is the value of Individual Harmonic Distortion on each order of harmonics. on the feeder panel connected to the source of harmonics has a value of VIHD at the 5 th order of $8.77 \%$. Graph 4.9 below explains the value of harmonics in each order under loading-unloading conditions. While in 3 other conditions there is no harmonic disturbance that exceeds the standard. Analysis on transient disturbance already meet the standard so no repair is needed. Conversely, the harmonic analysis in loading-unloading conditions has not met the standard so that it is done by using a passive filter. Installation of the passive filter affects the other 3 conditions so that the harmonics value on the condition of sailing, anchoring and maneuvering participate experienced the decrease.

\section{REFERENCES}

[1] M. R. Patel, Shipboard Electrical Power Systems. 2012

[2] 'Transient analysis of lossless transmission lines - IEEE Journals \& Magazine'. [Online]. Available: https://ieeexplore.iee.org/abstract/document/1447963. [Accessed: 19-Dec-2018].

[3] 'IEEE 45.1-2017 - IEEE Recommended Practice for Electrical Installations on Shipboard--Design'. [Online]. Available: https://standards.ieee.org/standard/45_1-2017.html. [Accessed: 19-Dec-2018].

[4] K. Sedghisigarchi and A. Feliachi, 'Dynamic and transient analysis of power distribution systems with fuel Cells-part II: control and stability enhancement', IEEE Trans. Energy Convers., vol. 19, no. 2, pp. 429-434, Jun. 2004.

[5] 'Transient analysis of a unified power flow controller and its application to design of the DC-link capacitor - IEEE Journals \& Magazine'. [Online]. Available:

https://ieeexplore.ieee.org/abstract/document/949506. [Accessed 19-Dec-2018].

[6] T. Athay, R. Podmore, and S. Virmani, 'A Practical Method for the Direct Analysis of Transient Stability', IEEE Trans. Power Appar. Syst., vol. PAS-98, no. 2, pp. 573-584, Mar. 1979.

[7] S. Sarwito, Semin, and T. Hidayaturrahman, 'Analysis of transient response first order and second order theory in pneumatic control system using feedback instrument type PCM140', in 2017 International Conference on Advanced Mechatronics, Intelligent Manufacture, and Industrial Automation (ICAMIMIA), 2017, pp. 155-160.

[8] I. R. Kusuma, S. Semin, M. B. Zaman, and F. M. Satrio, 'Designing Passive Harmonic Filter of Electric Propulsion System on Tanker Ship', Int. J. Mar. Eng. Innov. Res., vol. 2, no. 3, Jun. 2018

[9] N. Okada and K. Yukihira, 'Harmonic state estimation in distribution network based on fifth harmonic current characteristic', in 2014 16th International Conference on Harmonics and Quality of Power (ICHQP), 2014, pp. 566-570.

[10] E. S. Koenhardono, J. Prananda, and E. Danian, 'Analysis of Engine Propeller Matching of DC Motor as a Main Propulsion', Int. J. Mar. Eng. Innov. Res., vol. 2, no. 1, Dec. 2017.

[11] I. R. Kusuma, S. Sarwito, and R. A. W. A. Irawati, 'Analysis of Electric Propulsion Performance on Submersible with Motor DC, Supply Power 10260AH at Voltage 115VDC', Int. J. Mar. Eng. Innov. Res., vol. 1, no. 2, Mar. 2017. 